\title{
The impact of emotional health on fruit and vegetable consumption in young men: A qualitative study
}

\author{
Stephanie Howard Wilsher \\ University of Kent, Canterbury, Kent CT2 7TZ, UK
}

Increasing evidence suggests emotional health is associated with fruit and vegetable consumption (FVC). Individuals with negative affect eat less fruit and vegetables ${ }^{(1-3)}$. In fact, FVC differed by over one portion in people exhibiting positive and negative emotions ${ }^{(4)}$. People with poor diets tend to be less happy and healthy ${ }^{(3,5)}$ and people with negative personalities tend to opt for risky behaviours ${ }^{(6)}$. Despite the 5 a day campaign average fruit and vegetable consumption (FVC) in the UK is three portions per day, with young men consuming the least (2.9 portions). Little research has focussed on young men, but when older, men are at greater risk of early morbidity. The aim of the research was to assess whether emotional health of young men (18-24) may impact on their FVC. Such research is important for design of successful interventions to improve FVC and health.

A purposive sample (34) of young men (18-24) participated in eight focus groups segmented into high $(4+$ portions $)$ and low $(<3)$ fruit and vegetable consumers. Consumption was measured using four food diaries and/or 24 hour recalls. Focus group transcripts were analysed thematically into positive and negative emotions.

Young men with high FVC presented positive emotions: self-efficacy, enjoyment, satisfaction, alertness and emotional stability. Low consumers presented negative emotions: guilt, disgust, impatience, cynicism, stress. The difference of FVC between high and low consumers amounted to around two portions daily. Emotional health was instrumental for the level of FVC in the young men and may hint at personality differences as positive or negative emotions are commonly used to determine personality traits. If emotional health underlies FVC, then interventions such as cognitive behaviour therapy may be more effective than behavioural interventions, with a need for individualized rather than generalized health messages.

The Agriculture and Horticulture Development Board funded this research.

1. Konttinen H, Mannisto S, Sarlio-Lahteenkorva S, Silventoinen K \& Haukkala A. Appetite. [Article]. 2010 Jun;54(3):473-9.

2. Pronk N, Katz A, Gallagher J, Austin E, Mullen D, Lowry M et al. (2011) Population Health Management. 14(2), 59-67.

3. Kiviniemi MT, Duangdao KM. (2009) Appetite. [doi: 10.1016/j.appet.2009.02.006]. 52(3), 771-5.

4. Hearty A, McCarthy S, Kearney J, Gibney MJ (2007) Appetite. 48(1), 1-11.

5. Lyubomirsky S, King L, Diener E (2005) Psychological Bulletin. 131(6), 803-55.

6. Hong RY, Paunonen SV. Eur J Personal. [Article]. 2009 Dec;23(8), 675-96. 